\title{
Packaging's of the organic farming products in the context of circular economy
}

\author{
Piotr Kafel ${ }^{1, *}$, Pawet Nowicki ${ }^{1}$, and Magdalena Wojnarowska ${ }^{2}$ \\ ${ }^{1}$ Cracow University of Economics, College of Management Sciences and Quality, Department of \\ Quality Management, Rakowicka 27, 31-510 Krakow, Poland \\ ${ }^{2}$ Cracow University of Economics, College of Management Sciences and Quality, Department of \\ Technology and Ecology of Products, Rakowicka 27, 31-510 Krakow, Poland
}

\begin{abstract}
.
Research background: Food production is more and more globalized concerning not only the suppliers of food ingredients and producers but also considering the packaging trends and solutions available on the market. In opposition to that trend the EU high quality food products schemes were implemented such as organic farming products or traditional and regional ones. That products are usually perceived as good for the environment which is not always case when the packaging of that products are considered. The other global trend described in the paper that is focusing the attention is circular economy idea that points to the takeover from a linear economy to a circular economy. This paper combine the specific product (organic food) and its packaging with the recommendations of circular economy.

Purpose of the article: The purpose of the study was the question, if the studied companies that are under the strict obligatory surveillance according to the organic food production rules meet the requirements of the sustainable production and circular economy requirements.

Methods: Food processing manufacturers operating on a polish market were surveyed in the area of circular economy aspects concerning the use of the product packaging to indicate the level of implementation and real interest in sustainable development and circular economy.

Findings \& Value added: The main findings are related to the conclusion that organic farming producers with no implemented voluntary management system standards do not implement circular economy requirements.
\end{abstract}

Keywords: circular economy; plastic packaging; organic farming; 834/2007 regulation; management system standards.

JEL Classification: D22; Q56; L66

\footnotetext{
*Corresponding author: kafelp@uek.krakow.pl
} 


\section{Introduction}

Food production is more and more globalized concerning not only the suppliers of food ingredients and producers but also considering the packaging trends and solutions available on the market. In opposition to that trend the EU high quality food products schemes were implemented such as organic farming products or traditional and regional ones. That products are usually perceived as good for the environment which is not always case when the packaging of that products are considered. The other global trend described in the paper that is focusing the attention is circular economy idea that points to the takeover from a linear economy to a circular economy. This paper combine the specific product (organic food) and its packaging with the recommendations of circular economy.

\subsection{Organic farming products}

Organic farming products can be considered as high quality food products. Under the current EU law, the basic document containing the requirements for organic production is Council Regulation (EC) No 834/2007 of 28 June 2007 on organic production and labeling of organic products and repealing Regulation (EEC) No 2092/91 and the regulations implementing this Regulation. The production of organic foods is environmentally friendly; it does not utilize antibiotics, growth hormones, pesticides, chemical fertilizers or growth regulators. Organic foods are often regarded as more friendly to environmental agriculture and, ultimately, as healthier than conventional, non-organic foods [1].

The specific principles applicable to processing of organic food are [2]:

- the production of organic food from organic agricultural ingredients,

- the restriction of the use of food additives, of non organic ingredients and of micronutrients and processing aids,

- the exclusion of substances and processing methods that might be misleading regarding the true nature of the product,

- the processing of food with care, preferably with the use of biological, mechanical and physical methods.

Despite very strict regulations related to the processing of organic food, there are no requirements related to their packaging. Of course, organic food production processes promote natural balance, with environmentally friendly production and packaging, which positively affect consumers' buying behaviour [3-4]. Producers usually try to emphasize the ecological character of the product by using packaging design and materials that has positive associations with customers. However, these are voluntary activities not covered by the organic food control and certification system.

\subsection{Circular economy}

According to the recent European Union (EU) Action Plan on Circular Economy (CE) aims to create new employment and business growth through circular economy [5-6]. More CE is an economy where the value of products, materials and resources is maintained in the economy for as long as possible, and the generation of waste minimized [5]. The CE can be defined by the Ellen MacArthur Foundation as "an industrial economy that is restorative or regenerative by intention and design" [7].

In order to successfully change the model towards a circular economy, actions should start with changes at the very beginning of the product life cycle, i.e. from the design stage [8]. It is at this stage that decisions are made to what extent the materials used for production can be reused in the future. It is therefore important that, in the new economy, materials that are theoretically waste are recycled and reintroduced into the economy as a 
new raw material [9]. According to Barreiro-Gen and Lozano the popular way to implement the $\mathrm{CE}$ for organisations is to focus on reducing and recycling aspects. It is less common to focus on repairing and remanufacturing and in particular on internal $\mathrm{CE}$ efforts [10].

Considering the food in the $\mathrm{CE}$ perspective, there are free main dimensions such as [11]:

- source food grown regeneratively, and locally where appropriate,

- make the most of food (by-products into the bioeconomy),

- design and market healthier food products.

The above dimensions of CE for food can be discussed focusing on the packaging's. Food processing and distribution activities at the local level can reduce the need for excess packaging and shorten distribution supply chains [12]. The eco-design of products and processes in a supply chains also influence on the packaging of food products. While technical innovations such as biodegradable materials can help create compostable packaging, reimagining food product delivery models can eliminate some packaging needs altogether [11].

In a CE, important role have the waste management processes. Poor management of food waste and byproducts generated during food processing, distribution, and packaging further pollutes water, particularly in emerging economies [12]. Waste management plays a central role in the circular economy: it determines how the EU waste hierarchy is put into practice. The waste hierarchy establishes a priority order from prevention, preparation for reuse, recycling and energy recovery through to disposal, such as landfilling [5].

\section{Methods}

The purpose of the study was to investigate, if producers that are under the strict obligatory surveillance according to the organic food production rules meet the requirements of the sustainable production and circular economy requirements. In order to achieve the goal, the online survey was carried on.

Studied organizations were asked about implementation of voluntary management standards, the packages materials used for of organic products and changes that have been recently done in package materials. There were also questions concerning the opinion about more rigorous environmental requirements of the packaging of organic products. The last part of the survey included questions about the level of preparation for implementation of minimum content of recyclate in plastic packaging according to EU directive 904/2019.

According to official database obtained from national organic farming regulator, there were 910 certified organic food processors in 2018 year. The more recent database was not used because at least 2 years of participation in the organic certification system was assumed as a prerequisite for participation in the research. From that population there were randomly chosen 300 records and online survey was carried on. The questionnaire was send to top managers responsible for quality and food safety systems in organizations. There were 46 valid questioners obtained, representing 15,3 percent respond rate. The survey was made in September 2020. 


\section{Results}

\subsection{Organization's details and implemented standardize management systems}

Among the studied companies, all of them employed less than 250 employees. There were 17 organizations which employed from 2 to 10 people, 18 that employed between 11 and 50 people and 11 that employed between 51 and 250 employees.

Local food systems support food manufactured, processed and sold within a specific geographic area [13]. In spite of highly recommended by circular economy and some organic farming organizations and authorities operating on local markets only 2 studied companies indicated local and regional markets as the main scope of their products [14]. The remaining ones indicated the domestic and international markets as the range of their activities, respectively 24 and 20 companies. In that context the minimalization of used resources for transportation is in contradiction to circular economy.

All studied companies have implemented organic farming requirements according to Council Regulation (EC) No 834/2007 and obligatory food safety system - HACCP (hazard analysis and critical control point). Only those management standards were implemented in 28 companies. That group of studied organizations can be described as the one with low level of formalized management standardization. In table 1 there has been presented data related to the organizations from the second group that were classified according to the implementation of standardize and certify management systems. The second group of organizations was described as the group with higher level of formalized management standardization.

Table 1. Implemented management systems in studied organizations.

\begin{tabular}{|c|c|}
\hline Management standard & Number of companies \\
\hline ISO 9001 & 10 \\
\hline ISO 14001 & 9 \\
\hline ISO 22000 & 7 \\
\hline $\begin{array}{c}\text { PN-N 18001/ OHSAS } \\
18001 / \text { ISO 45001 }\end{array}$ & 5 \\
\hline IFS Food & 6 \\
\hline BRC Food & 5 \\
\hline Other standards/programs
\end{tabular}

Source: own study.

According to data presented in Table 1, most companies implemented standards that are typically implemented in food sector $[15,16]$. In case of ISO 14001 standard among studied companies the number of implementations is above the expected one only. This may drive to conclusion that ISO 14001 environmental management system, which goals are generally coincident with circular economy requirements is more popular among the group of organic food producers.

None of studied companies indicate cradle-to-cradle certification which is applied to products, that are result of clean production, recycling and reuse of waste products with a high content of the biologically active substances [17]. 


\subsection{Package materials of organic food}

One of the best strategy from the CE point of view, is not using package at all. Usually that kind of strategy is impossible to implement in practice. In studied companies only two of them indicated such conduct. Other organic products producers use package for their products. Most of them uses several different materials, only 36,9\% of studied producers uses one type of material as package.

The most commonly used package material was plastic $-58,7 \%$ in studied organization, which are considered by consumers as the environmentally unfriendly ones and could pose a threat to the environment [18]. Materials used for packaging of organic products has been presented in table 2. From that data, the biodegradable materials usage is very high. It is probably the effect of marketing strategy of organic products.

Table 2. Materials used for packaging of organic products.

\begin{tabular}{|c|c|c|c|c|c|}
\hline $\begin{array}{c}\text { Plastic } \\
\text { packaging }\end{array}$ & $\begin{array}{c}\text { Paper/ } \\
\text { paperboard }\end{array}$ & Glass & $\begin{array}{c}\text { Multilayer } \\
\text { laminate } \\
\text { materials }\end{array}$ & $\begin{array}{c}\text { Biodegradabl } \\
\text { e materials }\end{array}$ & Metal \\
\hline $58,7 \%$ & $47,8 \%$ & $39,1 \%$ & $23,9 \%$ & $23,9 \%$ & $8,6 \%$ \\
\hline
\end{tabular}

Source: own study.

New law regulations, supplies and consumers requirements or environmental care force the organizations to take innovative activities. In table 3 . there are changes that have been recently done in package materials by surveyed organizations.

Table 3. Changes that have been recently done in package materials.

\begin{tabular}{|c|c|}
\hline List of implemented changes & $\begin{array}{c}\text { Number of } \\
\text { answers [\%] }\end{array}$ \\
\hline Use of biodegradable packaging & $23,9 \%$ \\
\hline $\begin{array}{c}\text { Changes in the design of the packaging allowing for their } \\
\text { easier recycling }\end{array}$ & $21,7 \%$ \\
\hline $\begin{array}{c}\text { Other changes to the packaging material to be "more } \\
\text { environmentally friendly" }\end{array}$ & $21,7 \%$ \\
\hline Reduction of packaging weight & $17,4 \%$ \\
\hline $\begin{array}{c}\text { Introducing a requirement for the use of recyclate for the } \\
\text { production of plastic packaging }\end{array}$ & $13 \%$ \\
\hline $\begin{array}{c}\text { Resignation from product packaging } \\
\text { No changes }\end{array}$ & $2,2 \%$ \\
\hline
\end{tabular}

Source: own study.

Only $56,5 \%$ of organizations implemented some changes in recent time in package materials. In that group, usually more than one change was indicated. When comparing the group of companies that are changing the package materials the strong relation to implementation of management standards such as ISO 9001, IFS, BRC is visible. That results are in line with Chrysochou and Festila [4] study, where the package designs of organic products differ from those of conventional products based on the presence of more paper material, white and green colours and images displaying nature. All that changes helps to communicate and position a product as organic one. The changes in materials can also be support communication with customers highlighting environmentally friendly character of the products are presented in Table 3. 
Circular economy is a concept that requires from the food producers greater involvement in the development of pro-environmental activities. Not only strictly according to the organic farming requirements that are mainly focused on the food ingredients but also from the perspective of all processes that are performed in company. At the same time, organic food producers are perceived by customers as organizations that act in this way. Figure 1 shows the surveyed opinion about more rigorous environmental requirements of the packaging of organic products. Figure 2 contains a summary of the opinions results concerning the more rigorous impact of the production processes on the natural environment.

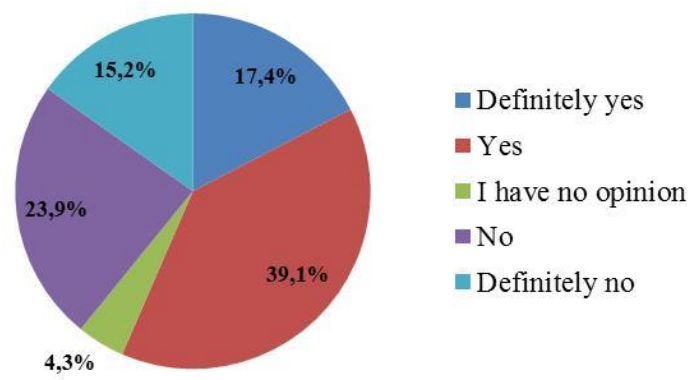

Fig. 1. Organic food producers opinion about more rigorous environmental requirements of the packaging of organic products.

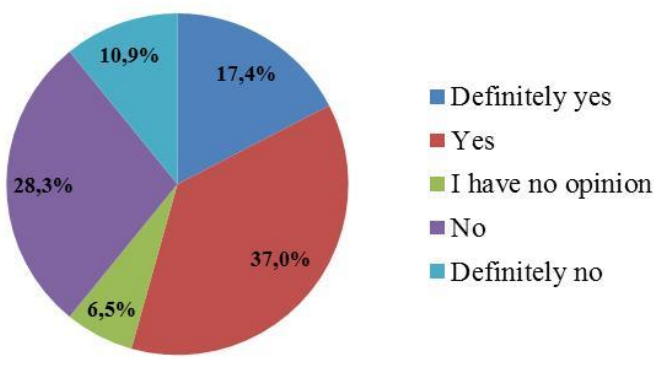

Fig. 2. Organic food producers opinion about the more rigorous impact of the production processes on the natural environment.

Results presented on figure 1 and 2 are quite similar and indicate that the majority of respondents proving the need to introduce more rigorous environmental requirements for all processors of organic food. Both in terms of the impact of production activities on the natural environment $(54,3 \%)$ and the type of used organic food packaging $(56,5 \%)$.

Plastic package materials according to the (EU) 2019/904 directive should be minimized. One of the regulations from the directive, forces producers to use recycled polyester (r-PET) materials where at least $25 \%$ of products are from recycled material. That goal should be obtained utill 2025 [19]. In Table 4 and 5, the level of preparation was presented among 27 studied companies that are using PET materials.

The preparation of organic food producers to meet the minimal requirements of the amount of recyclate in PRT materials used as food package is low. Most of studied do not have the awareness of the upcoming changes and the necessary changes resulting from it. 
Table 4. Level of preparation for implementation of minimum content of recyclate in plastic packaging

\begin{tabular}{|c|c|}
\hline Organizations preparation for the changes & $\begin{array}{c}\text { Number of } \\
\text { organizations }\end{array}$ \\
\hline Yes, we are prepare for the changes & 7 \\
\hline No, we are not prepare for the changes & 2 \\
\hline Don't know, we haven't conducted such analyzes yet & 18 \\
\hline
\end{tabular}

Source: own study.

Table 5. Level of preparation for implementation of minimum content of recyclate in plastic packaging

\begin{tabular}{|c|c|}
\hline $\begin{array}{c}\text { Percentage of recyclate in currently used plastic } \\
\text { materials }\end{array}$ & $\begin{array}{c}\text { Number of } \\
\text { organizations }\end{array}$ \\
\hline No recyclate in package & 3 \\
\hline$<25 \%$ & 4 \\
\hline $25-50 \%$ & 1 \\
\hline$>50 \%$ & 3 \\
\hline Don't know, we haven't got such information & 16 \\
\hline
\end{tabular}

Source: own study.

As in the case of introducing biodegradable materials, organizations that indicated their readiness to meet the requirements of Directive 904/2019 were characterized by a higher level of implementation of formalized quality and safety management systems. Representatives of the smallest organizations (employing up to 10 people) indicated that the verification of the legal requirements for packaging is an obligation of their producers.

\section{Discussion}

From the results obtained within the study, it can be concluded that almost half of studied companies do not implement circular economy requirements in the context of organic food package. Thanks to such attributes as price, convenience and safety, plastic is still the most popular form of organic product packaging material. Nevertheless, some hopes may be associated with attempts to introduce changes to packaging materials or other proenvironmental measures by studied producers.

When comparing the group of companies that have implemented some voluntary management or food safety systems with the group of organizations without that systems it can be concluded that in the first group, the circular economy requirements are more often put into practice. On the other side those producers usually operate on a global markets while local activities are supported in more circular approach.

Interestingly, the majority of respondents support the need to introduce more rigorous environmental requirements for organic food processors. That changes should concern both more sustainable production and less environmentally harmful packaging of organic products.

The main limitation of the analysis is that it covers only the Polish organic farming food producers. It opens for future research directions about the linkage between circular 
economy and other than organic high quality products which are commonly perceived by consumers as environmental leaders.

The Project has been financed by the Ministry of Science and Higher Education within "Regional Initiative of Excellence" Programme for 2019-2022. Project no.: 021/RID/2018/19. Total financing: 11897 131,40 PLN.

\section{References}

1. Lee, T. H., Fu, C. J.; Chen, Y. Y. (2019). Trust factors for organic foods: consumer buying behavior. British Food Journal, 122, 414-431.

2. EU. (2007). Council Directive 834/2007 on organic production and labelling of organic products.

3. Onwezen, M.C. (2015). I did good, and we did bad: The impact of collective versus private emotions on pro-environmental food consumption. Food Research International, 76, 261-268.

4. Chrysochou, P., Festila, A. (2019). A content analysis of organic product package designs. Journal of Consumer Marketing, 36, 441-448.

5. European Commision. (2015). Communication of 2.12.2015 on an EU action plan for the circular economy.

6. Ünal, E., Urbinati, A., Chiaroni, D. (2018). Managerial practices for designing circular economy business models. Journal of Manufacturing Technology Management, 30, 561-589.

7. Ellen MacArthur Foundation (2013). Towards the Circular Economy: Opportunities for the consumer goods sector. Towards the Circular Economy.

8. Tecchio, P., McAlister, C., Mathieux, F., Ardente, F. (2017). In search of standards to support circularity in product policies: A systematic approach. Journal of Cleaner Production, 168, 1533-1546.

9. Saidani, M., Yannou, B., Leroy, Y., Cluzel, F. (2017). How to assess product performance in the circular economy? Proposed requirements for the design of a circularity measurement framework. Recycling, 2, 6.

10. Barreiro-Gen, M., \& Lozano, R. (2020). How circular is the circular economy? Analysing the implementation of circular economy in organisations. Business Strategy and the Environment, 1-11.

11. Ellen MacArthur Foundation (2019). Cities and Circular Economy for Food Cities. 173.

12. Geissdoerfer, M., Morioka, S. N., de Carvalho, M. M., Evans, S. (2018). Business models and supply chains for the circular economy. Journal of Cleaner Production, 190, 712-721.

13. Zuba-Ciszewska, M., Kowalska, A., Manning, L., Brodziak, A. (2019). Organic milk supply in Poland: market and policy developments. British Food Journal, 121, 33963412.

14. Codex Alimentarius (2013). Guidelines for the production, processing, labelling and marketing of organically produced foods. Cac/Gl 1999, 1-52.

15. Kafel, P., Casadesus, M. (2016). The order and level of management standards implementation: Changes during the time. TQM Journal, 28, 636-647.

16. ISO (2018). The ISO Survey of Management System Standard Certifications. 
17. Topleva, S.A., Prokopov, T.V. (2020). Integrated business model for sustainability of small and medium-sized enterprises in the food industry. British Food Journal, 122, 1463-1483.

18. Adeyeye, S.A.O. (2019). Food packaging and nanotechnology: safeguarding consumer health and safety. Nutrition \& Food Science, 49, 1164-1179.

19. EU (2019). Directive (Eu) 2019/904 of the European Parliament and of the Council of 5 June 2019 on the reduction of the impact of certain plastic products on the environment. 